\title{
Assess the Relation between Emotional Intelligence and Quality of Life among the Nursing Faculties
}

\author{
Mrs. Sundari Apte ${ }^{1}$, Mrs. Anita Khandagle ${ }^{2}$
}

Keywords: Relation, Emotional Intelligence, Quality Of Life, Nursing Faculties.

Mayer and Salovey in 1997 defined Emotional Intelligence as the ability to perceive accurately, appraise, and express emotion; the ability to access and/or generate feelings when they facilitate thought; the ability to understand emotion and emotional knowledge; and the ability to regulate emotions to promote emotional and intellectual growth.

Quality of life: As per Research unit of Toronto University, it is the degree of enjoyment to important possibilities of one's life. The possibilities are the opportunities and limitations an individual has in their life which reflect the interaction of personal and environment factors. The enjoyment has two components- experiencing the satisfaction and achieving some characteristic. They identified three domains which are: Being, Belonging, and Becoming. Being includes Physical, Psychological and Spiritual being; Belonging includes - Physical, Social and Community; Becoming includes - Practical, Leisure and Growth.

Anil K choubey, Santosh. K. Singh and Rakesh Pandey conducted a study on role of emotional intelligence in stress and health. The study was conducted on 209 adults from different occupations in the age group of 21-50 yrs and found that emotional intelligence is associated with better health and lower stress level. Among the dimensions of emotional intelligence, ability to manage emotion in self was found to be the best predictor of stress and health.

Austin, Saklofske, \& Egan conducted a study on Emotional intelligence and psychological wellbeing and found it was positively correlated like life satisfaction and happiness, while associations with measures of mental ill-health such as depression, stress and loneliness have been found to be negative. Positive associations of EI with higher levels of self rated physical health have also been reported by researchers.

He also found that there was a correlation between emotional intelligence and personality traits, health and well-being

\footnotetext{
${ }^{1}$ Assistant Professor, Bharati Vidyapeeth college of Nursing Pune

${ }^{2}$ Associate Professor, Sadhu Vaswani College of Nursing Pune

*Responding Author

(C) 2016, S Apte, A Khandagle; licensee IJIP. This is an Open Access Research distributed under the terms of the Creative Commons Attribution License (http://creativecommons.org/licenses/by/2.0), which permits unrestricted use, distribution, and reproduction in any Medium, provided the original work is properly cited.
} 
In a cross sectional quantitative study to investigate the extent to which emotional labour and emotional intelligence are associated with well-being and job-stress among a group of Australian community nurses. It was found that the moderating role of emotional intelligence was evaluated as a key factor in the rescue of healthcare workers from job-stress, thus increasing job retention. The subjects were Australian community nurses $(n=312)$ reported on their perceived emotional labour, emotional intelligence and their levels of well-being and job stress using a paper and pencil survey. Results support the hypothesis that both emotional labour and emotional intelligence have significant effects on nurses' well-being and perceived job-stress. Thus it is found that Emotional intelligence plays a moderating role in the experience of job-stress.

Sathya Kumar, J.; Iyer, Vidya Rajaram conducted an exploratory study to find the correlation between Emotional Intelligence and Quality of Work-Life among Employees in the Educational Institutions as it is one sector of employment where it is said quality of work life at times is very challenging. The sample consisted of individuals employed in various academic institutions in and around Madurai. Questionnaires were administered to assess their level of emotional intelligence and the quality of work life as perceived by them. Using the statistics it was seen that there exist a positive correlation between the emotional intelligence and the quality of work life of the individuals. Difference was also found among teaching and non teaching staffs.

\section{NEED OF THE STUDY:}

With the increase in the demand of nurses all over the world especially increasing demand for Indian nurses have led to increase in the numbers of Nursing college. Thus the faculties of nursing need to be emotionally stable and intelligent which in turn will affect on their quality of life. Keeping this aspect in view the present study was taken up for research.

\section{Problem statement:}

A study to assess the relation between emotional intelligence and quality of life among nursing faculties from selected colleges of Pune City.

\section{Objectives:}

- To assess the emotional intelligence level among the nursing faculties from selected colleges of Pune City

- To assess the quality of life among the nursing faculties from selected colleges of Pune city

- To find the relation between emotional intelligence and quality of life

- To find an association between selected demographic variables and quality of life.

- To find an association between selected demographic variables and emotional intelligence. 


\section{Assumptions:}

- There will be correlation between quality of life and emotional intelligence.

- The qualification will show association with emotional intelligence

\section{MATERIAL AND METHODS:}

Research methodology: Research Approach was quantitative approach; Research Design was Exploratory Survey design; Target Population - Nursing faculties; Sampling techniques - Non probability - Purposive sampling technique; Sample - Nursing faculties from selected colleges of Pune city who fulfil the inclusion criteria. Sample size - 121; Inclusion Criteria - Nurses willing to participate in the study and exclusion criteria - Nurse faculties with one of experience after the basic training.

The tool consists of 3 sections. Section I consists of demographic data with 8 questions. The section II consists of self reported emotional intelligence questionnaire with 50 questions which are further divided into 5 dimensions and section III consists of quality of life questionnaire with 26 questions covering all the four domains as given by WHO. The score obtained are further categorized into adjectives like needs improvement, strength, good, and fair.

The reliability of the tool was found to be $r=8.4$ using Guttmann's split half methods when carried out on 25 subjects.

After formal permission, pilot study was done on 25 subjects and was found to be feasible The main study was conducted from Dec 2015 to Mid of Feb 2016.

\section{RESULTS:}

Section I - Demographic data in frequency and percentage

Section II - Emotional Intelligence distribution

Section III - Quality of life Distribution

Section IV - Correlation between Emotional Intelligence and quality of Life

Section V - Association of demographic variables with emotional intelligence and quality of Life 
Section I: Demographic Data

\section{Age in Percentage $\quad \mathbf{N}=121$}

$$
\square 20 \text { - 30y } \square 30-40 \mathrm{y} \quad \square 40-50 \mathrm{y} \quad \square>50 \mathrm{y}
$$

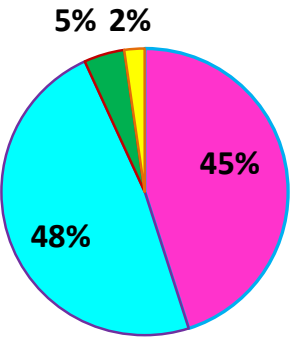

Fig 1 Demographic data - Age of the subjects in percentage, $N=121$

The figure one shows the age distribution in percentage and maximum subjects under study were in the group of $30-40$ years with $48 \%$ and minimum subjects were in the group of more than 50 Yrs of age with $2 \%$.

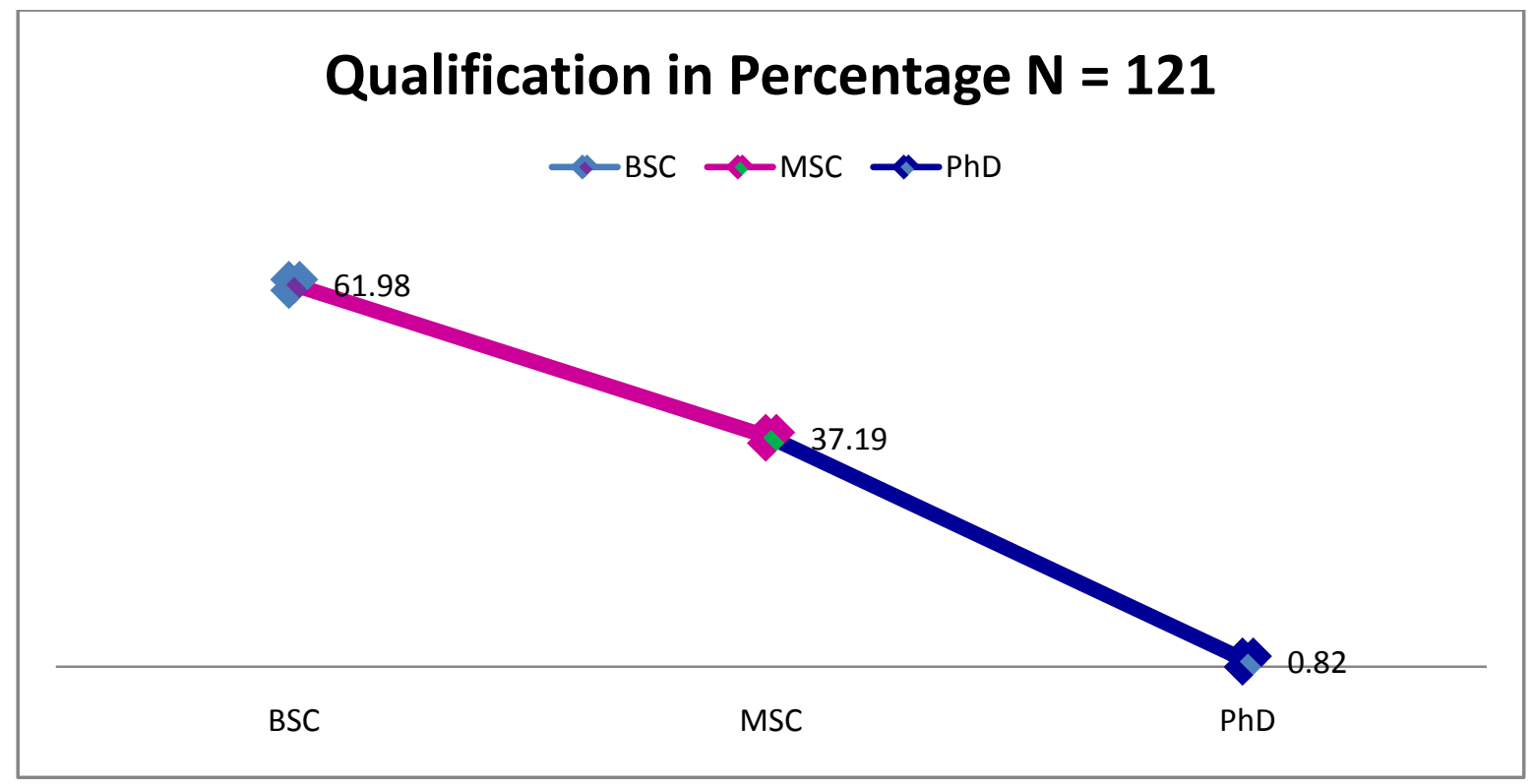

Fig 2 Demographic Data - Qualification of the subjects in percentage, $N=121$

Figure Two shows the distribution of the subjects based on their professional qualification. Maximum subjects qualification was B Sc Nursing with 61.98percentage and minimum subjects were $\mathrm{Ph} \mathrm{D}$ in nursing with0.82 percentage. 
Table 1: Demographic data in frequency and percentage, $N=121$

\begin{tabular}{|l|l|l|}
\hline \multicolumn{1}{|c|}{ Demographic Data } & Frequency (f) & Percentage (\%) \\
\hline Gender & 7 & 5.78 \\
\hline Male & 114 & $\mathbf{9 4 . 2 1}$ \\
\hline Female & & \\
\hline Family type & 92 & $\mathbf{7 6 . 0 3}$ \\
\hline Nuclear & 29 & 23.96 \\
\hline Joint & & \\
\hline Religion & 72 & $\mathbf{5 9 . 5}$ \\
\hline Hindu & 44 & 36.36 \\
\hline Christian & 3 & 2.47 \\
\hline Others & 2 & 1.65 \\
\hline Muslims & &
\end{tabular}

Above table gives information regarding the demographic data of the subjects, shows that maximum subjects were female with 94.21percentage; regarding their family type maximum were from nuclear family with 76.03 percentage; in the religion maximum were Hindu with 59.5 percentage and 1.65 percentage were Muslims.

Table 1: Demographic data in frequency and percentage (Cont..,) $N=121$

\begin{tabular}{|l|l|l|}
\hline \multicolumn{1}{|c|}{ Demographic Data } & Frequency (f) & Percentage (\%) \\
\hline Income of the family & & \\
\hline $10-50000$ & 54 & $\mathbf{4 4 . 6 2}$ \\
\hline $50-100000$ & 36 & 29.75 \\
\hline $10-150000$ & 11 & 9.09 \\
\hline$>150000$ & 20 & 16.52 \\
\hline Position & & \\
\hline Clinical Instructor & 28 & 23.14 \\
\hline Tutor & 40 & 33.05 \\
\hline Lecturer & 44 & 36.36 \\
\hline Asst professor & 8 & 6.61 \\
\hline Professor & 1 & 0.82 \\
\hline & &
\end{tabular}

Regarding the family income of the subjects family maximum subjects had their income range in 10000 to 50,000 with 44.62 percentage and minimum had 100000 - 150000 per month as their income with 9.09 percentage. In respect to their position in the teaching college, maximum were in the lecturers post with 36.36 percentages and minimum were professor with 0.82 percentages. 


\section{Section II}

Table 2. Distribution of emotional Intelligence Score. $N=121$

\begin{tabular}{|c|c|c|c|c|}
\hline $\begin{array}{l}\text { Emotional } \\
\text { Intelligence }\end{array}$ & Categories & $\begin{array}{l}\text { Frequency } \\
(f)\end{array}$ & Percentage (\%) & \multirow{11}{*}{$\begin{array}{l}\text { Grading } \\
1-15 \mathrm{M} \text { - work on it } \\
16-30 \mathrm{M}-\text { Needs attention } \\
31-50 \mathrm{M} \text { - Strength }\end{array}$} \\
\hline \multirow{2}{*}{$\begin{array}{l}\text { Self } \\
\text { awareness }\end{array}$} & Needs attention & 12 & 9.91 & \\
\hline & Strength & 109 & 90.08 & \\
\hline \multirow{2}{*}{$\begin{array}{l}\text { Managing } \\
\text { emotion }\end{array}$} & Needs attention & 23 & 19 & \\
\hline & Strength & 98 & 80.99 & \\
\hline \multirow{2}{*}{$\begin{array}{l}\text { Motivating } \\
\text { oneself }\end{array}$} & Needs attention & 12 & 9.91 & \\
\hline & Strength & 109 & 90.08 & \\
\hline \multirow[b]{2}{*}{ Empathy } & Needs attention & 7 & 5.78 & \\
\hline & Strength & 114 & 94.21 & \\
\hline \multirow{2}{*}{$\begin{array}{l}\text { Social } \\
\text { Skills }\end{array}$} & Needs attention & 6 & 4.95 & \\
\hline & Strength & 115 & 95.04 & \\
\hline
\end{tabular}

In the study it was found that maximum faculties had the best grades in emotional intelligence which looks at 5 aspects of emotional intelligence. The aspects are self awareness, managing emotions, motivating oneself, empathy and social skills. The grading was into 3 categories which were: work on it, needs attention and Strength. The results are as above in the table. Around 6\% and $5 \%$ of the subjects needs to pay attention in regard to empathy and social skills respectively. In managing emotions 19 percentage of subject needs to pay attention towards it

\section{Section III}

\section{Quality of Life in percentage}

$\mathbf{N}=121$

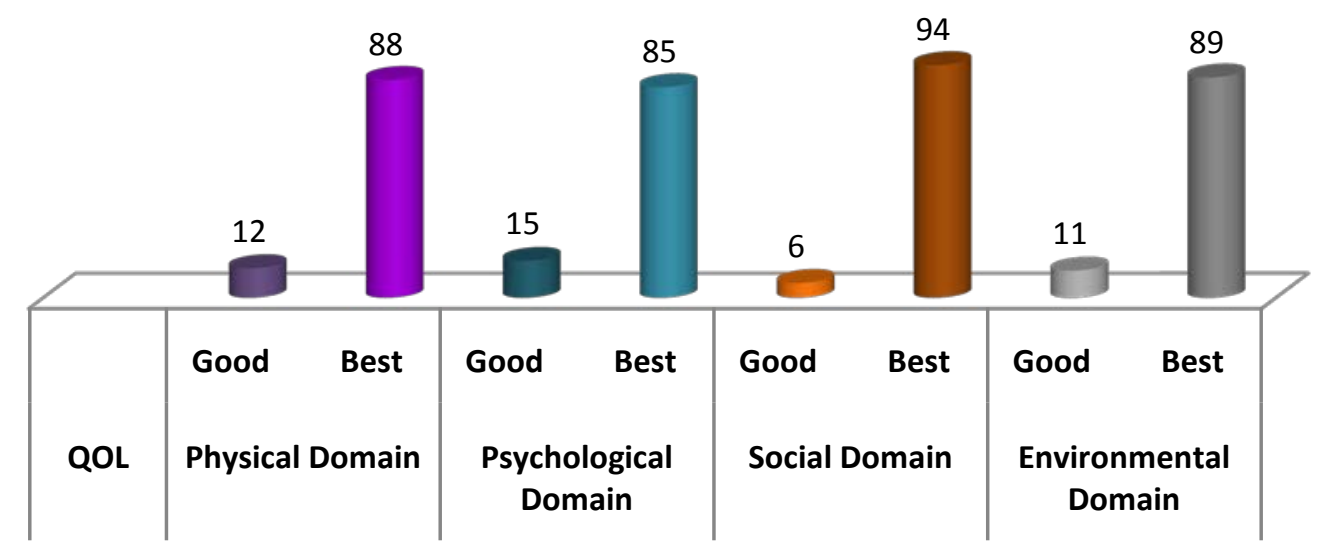

Fig 3: Quality of life of the subjects in percentage, $N=121$ 
With regard to Quality of life (QOL) it was found that 6 - 15 percent needs to work more in all the domains of quality of life. The maximum scores were found to be in social domain, followed by environmental, physical domain and psychological domain.

\section{Section IV}

Table 3: Correlation between emotional intelligence and quality of Life $\quad N=121$

\begin{tabular}{|l|l|l|l|l|}
\hline Variables & Mean & Median & St Dev & Correlation \\
\hline Emotional Intelligence & 60.5 & 60.5 & 51.51 & \multirow{2}{*}{$\mathbf{0 . 9 9 3 8 0 5}$} \\
\hline Quality of Life & 60.5 & 60.5 & 49.99 & \\
\hline
\end{tabular}

The table three shows that the correlation between emotional intelligence and quality of life is $r=0.993805 w h i c h$ is highly significant.

\section{Section V}

Table 4 Association of demographic data with Emotional intelligence and Quality of Life $N=121$

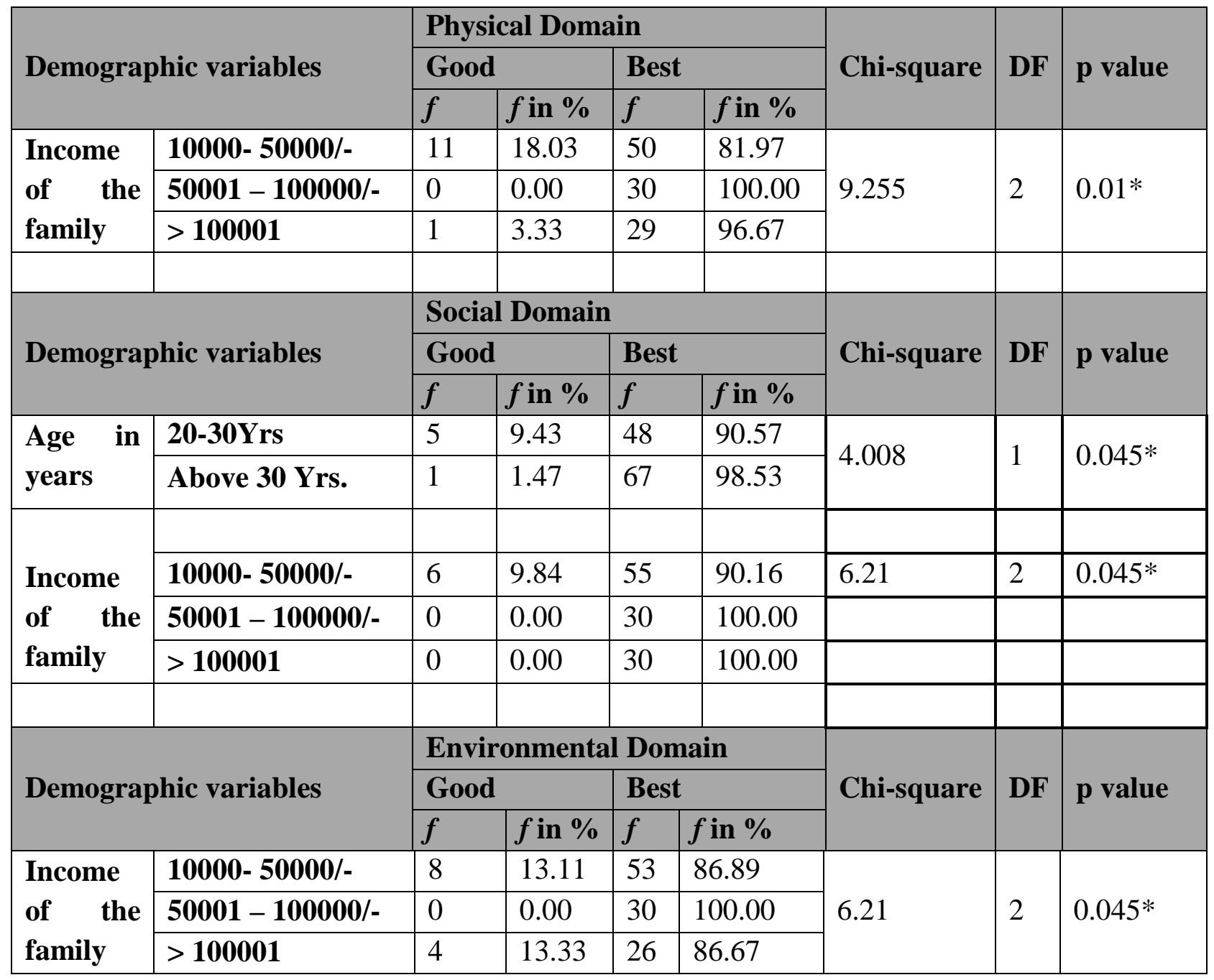


Table four shows the association of demographic variables with quality of life and emotional intelligence. It was found statistically, there was no association of demographic variables with emotional intelligence. However there was association of Quality of life with demographic variables which can be seen in the table There was an association between income of the family with the physical domain with p values at 0.01 ; In social domain there was association with age and income of the family with $\mathrm{p}$ value 0.045 each; Environmental domain also showed association with the income of the family with 0.045 , the $\mathrm{p}$ value. No other variables were found to be associated with any of the domain of the quality of life.

\section{DISCUSSION:}

The study conducted by Jennifer C H Min on tour guides emotional intelligence in relation to demographic variables indicates that there were differences between the individuals' EI in relation to the variables of gender and length of service. Where as in the present study we found no association between EI and demographic data but the Quality of life was associated with age and Income of the family.

\section{IMPLICATIONS:}

This tool may be of some use while inducting students into nursing profession. The nursing faculties also should consider the emotional intelligence into consideration while dealing with the students. Many more research should be conducted in this subject. Emotional intelligence should be included into the curriculum of the nursing students to encourage the importance of it in our daily living.

\section{REFERENCES/ BIBLIOGRAPHY:}

Anil Kumar Choubey*, Santosh Kumar Singh* and Rakesh Pandey Role of Emotional Intelligence in Stress and Health Indian Journal Social Science Researches Vol. 6, No. 1, March, 2009, pp. 122-134

Austin, Saklofske, \& Egan, 2005; Dawda \& Hart, 2000; Day, Therrien, \& Carroll, 2005;

Jennifer C. H. Min Tour guides' emotional intelligence in relation to demographic characteristics African journal of business management 4(15):3730-3737 • January 2011

KARIMI L, LEGGAT S G, DONOHUE L, FARRELL G. \& COUPER G.E .(2 0 ( 1 3) Emotional rescue: the role of emotional intelligence and emotional labour on well-being and jobstress among community nurses. Journal of Advanced Nursing 00(00), 000-000. doi: 10.1111/jan.12185

Personality, well-being and health correlates of trait emotional intelligence. Personality and Individual Differences, 38, 547-558. ${ }^{2}$ 